https://helda.helsinki.fi

\title{
Anemia and low-grade inflammation in pediatric kidney transplant recipients
}

\section{Miettinen, Jenni}

2017-02

Miettinen , J , Tainio , J , Jahnukainen , T , Pakarinen , M , Lauronen , J \& Jalanko , H 2017 ,

' Anemia and low-grade inflammation in pediatric kidney transplant recipients ', Pediatric Nephrology , vol. 32 , no. 2 , pp. 347-358 . https://doi.org/10.1007/s00467-016-3481-7

http://hdl.handle.net/10138/232263

https://doi.org/10.1007/s00467-016-3481-7

publishedVersion

Downloaded from Helda, University of Helsinki institutional repository.

This is an electronic reprint of the original article.

This reprint may differ from the original in pagination and typographic detail.

Please cite the original version. 


\title{
Anemia and low-grade inflammation in pediatric kidney transplant recipients
}

\author{
Jenni Miettinen $^{1}$ (D) Juuso Tainio ${ }^{1} \cdot$ Timo Jahnukainen $^{1} \cdot$ Mikko Pakarinen $^{1} \cdot$ \\ Jouni Lauronen ${ }^{2} \cdot$ Hannu Jalanko ${ }^{1}$
}

Received: 23 March 2016 /Revised: 23 July 2016 / Accepted: 27 July 2016 /Published online: 30 August 2016

(C) IPNA 2016

\begin{abstract}
Background Anemia and low-grade inflammation are reported to be associated with impaired long-term graft outcome in renal transplant (RTx) recipients. In this study, hemoglobin $(\mathrm{Hb})$ and inflammation marker levels were correlated with measured glomerular filtration rate (GFR) in 128 pediatric RTx recipients over a median follow-up period of 10 years. Methods Serum levels of erythropoietin (EPO), hepcidin-25, high-sensitivity C-reactive protein (CRP) (hsCRP) and interleukin-6 (IL-6) were analyzed by enzyme-linked immunosorbent assays, and GFR was analyzed by ${ }^{51} \mathrm{Cr}$-EDTA clearance.

Results The median levels of $\mathrm{Hb}(115 \mathrm{~g} / \mathrm{L})$, hsCRP $(0.4 \mathrm{mg} / \mathrm{L})$ and IL-6 $(1.4 \mathrm{pg} / \mathrm{mL})$ and the median erythrocyte sedimentation rate (ESR; $19 \mathrm{~mm} / \mathrm{h}$ ) remained stable after the first postoperative year. However, approximately half of the patients had a normocytic, normochromic anemia, and one-third had elevated levels of hsCRP $(>1 \mathrm{mg} / \mathrm{L})$ and ESR $(>25 \mathrm{~mm} / \mathrm{h})$, indicating continuous low-grade inflammation. Low $\mathrm{Hb}$ levels preceded increased fibrosis in protocol biopsies taken at 1.5 and 3 years after transplantation and preceded decreased GFR by several years. Hb levels showed an inverse correlation with EPO levels $(r=-0.206, p=0.038)$ and ESR $(r=-0.369, p<0.001)$, but not with hepcidin-25, hsCRP or IL-6 levels. The levels of the major inflammatory markers IL-
\end{abstract}

Jenni Miettinen

jenni.v.miettinen@helsinki.fi

1 Children's Hospital, University of Helsinki and Helsinki University Hospital, Helsinki, Finland

2 Histocompatibility Laboratory, Finnish Red Cross Blood Service, Helsinki, Finland
6 and hsCRP did not show a significant correlation with GFR at either the early maintenance phase or later. In the multivariable analysis, low $\mathrm{Hb}$ levels performed better than any other marker with respect to predicting concomitant and subsequent GFR.

Conclusions Anemia, but not elevated inflammatory indices, was associated with poor concomitant and subsequent graft function during a 10-year follow-up in pediatric RTx patients.

Keywords Anemia $\cdot$ Inflammation $\cdot$ Children $\cdot$ Glomerular filtration rate $\cdot$ Renal transplantation

\section{Introduction}

Anemia and low-grade inflammation are common complications in renal transplant (RTx) recipients. Every second pediatric RTx recipient is anemic according to the recently published registry data of over 3600 European patients [1]. In adults, the prevalence of post-transplantation anemia varies around $40 \%$ [2-4]. Both in children and adults, crosssectional analyses have shown an association between low hemoglobin $(\mathrm{Hb})$ levels and reduced graft function $[1,5,6]$. Similarly, low-grade inflammation, which often induces anemia, has been associated with decreased patient and graft survival, especially in adults [7-9]. Thus, knowledge of the underlying mechanisms is important.

The pathophysiology of anemia and inflammation in RTx patients is believed to be multifactorial. Sufficient allograft function is required for adequate erythropoietin (EPO) production to maintain erythropoiesis. EPO deficiency in the early phase after transplantation would appear to recover within the first year post-transplantation in most patients [10-12]. At the maintenance phase, impaired production or EPO resistance may, however, account for the high prevalence of 
anemia. In general, increased inflammatory activity typically causes EPO resistance [13-15]. Inflammatory stimulus is an activator of the rapid production of cytokines and acute phase proteins, such as interleukin-6 (IL-6) and C-reactive protein (CRP). IL-6 is the main inducer of CRP production [16] and also stimulates hepatic secretion of hepcidin-25, a peptide which links iron availability and requirements as it regulates iron homeostasis via the iron transporter ferroportin [17, 18]. Suppressed erythropoiesis and excess iron increases the synthesis of hepcidin-25. Reduced graft function may lead to elevated serum levels of hepcidin-25 due to reduced urinary excretion [19].

Although anemia has been shown to be associated to decreased graft function, the role of low-grade inflammation and other anemia-related risk factors on graft function remains unexplored. The aims of this study were (1) to evaluate longitudinally the prevalence of low $\mathrm{Hb}$ and high levels of inflammatory markers at the maintenance phase $(>1$ year after transplantation) in pediatric RTx patients, (2) to identify anemia-related factors, such as blood count findings and EPO and hepcidin-25 levels at the early maintenance phase, when chronic allograft injury is rare and graft function is good, (3) to analyze the association between $\mathrm{Hb}$ levels and the inflammation markers high-sensitivity CRP (hs-CRP), IL-6 and erythrocyte sedimentation rate (ESR), (4) to study how the $\mathrm{Hb}$ levels associate with the kidney biopsy findings and, especially, how the $\mathrm{Hb}$ and inflammation marker levels correlate with concomitant and future glomerular filtration rate (GFR).

\section{Materials and methods}

\section{Patients}

This longitudinal analysis of post-renal transplantation $\mathrm{Hb}$ and inflammation marker levels was retrospectively performed in 128 pediatric patients who were transplanted at the study center between August 1988 and March 2006 and for whom stored serum samples were available for extensive laboratory analyses. All patients made regular visits to the transplant center at 3- to 6-month intervals during the first 2 years after renal transplantation and annually thereafter until transfer to adult care. Data on diagnosed acute rejection or immunoactivation in fine needle biopsies (used until 2000) during the first year and donor age were available for 78 (61 \%) patients transplanted since 1997. Nine patients had undergone re-transplantation. In total, 11 grafts were lost, of which nine were lost due to chronic rejection, one due to membranous glomerulonephritis and one due to hemolytic-uremic syndrome. In addition, six patients died 4-15 years after renal transplantation.

All patients received triple-drug immunosuppression that included a calcineurin inhibitor (cyclosporine A or tacrolimus), an antimetabolite (azathioprine or mycophenolate) and low-dose methylprednisolone, as previously reported [20]. While azathioprine + cyclosporine A was the major combination therapy in the 1990 s, the use of mycophenolate + tacrolimus increased in subsequent years. The drug combinations and dosing (blood levels) were, however, individualized according to rejection history, HLA-matching and observed side effects. Exogenous EPO was given to three patients (2.4\%) at 18-24 months after renal transplantation, 16 patients $(14 \%)$ at 6 years and 30 patients $(35 \%)$ at 10 years. EPO users were excluded from the measurements of the endogenous EPO levels taken at 1.5-4 years after renal transplantation.

\section{Laboratory data}

Clinical data and annual blood parameters were retrospectively obtained from the medical records. Anemia was defined according to age and gender-adjusted reference values of $\mathrm{Hb}$ for children: $\mathrm{Hb}<112 \mathrm{~g} / \mathrm{L}$ (age 1-7 years), $\mathrm{Hb}<116 \mathrm{~g} / \mathrm{L}$ (age $8-11$ years), $\mathrm{Hb}<120 \mathrm{~g} / \mathrm{L}$ (age $12-15$ years, girls), $\mathrm{Hb}<124 \mathrm{~g} / \mathrm{L}$ (age $12-13$ years, boys), $\mathrm{Hb}<130 \mathrm{~g} / \mathrm{L}$ (age $14-15$ years, boys) and $\mathrm{Hb}<117 \mathrm{~g} / \mathrm{L}$ in women and $\mathrm{Hb}<134 \mathrm{~g} / \mathrm{L}$ in men. Severe anemia was defined as $\mathrm{Hb}<100 \mathrm{~g} / \mathrm{L}$. Leucopenia and thrombocytopenia were defined according to age-adjusted reference values as follows: leucocytes $<3.4-5 \times 10^{9} / \mathrm{L}$ and thrombocytes $<150-200 \times 10^{9} / \mathrm{L}$. The neutropenia level was set to $<1.0 \times 10^{9} / \mathrm{L}$.

GFR was measured using ${ }^{51} \mathrm{Cr}$-EDTA clearance with the modified Brochner-Mortensen equation [21, 22], and acceptable distribution values were between 15 and $35 \%$. GFR was measured on every control visit, and the annual GFR decline (in $\mathrm{mL} / \mathrm{min} / 1.73 \mathrm{~m}^{2}$ per year) was assessed in each patient from 1.5 years post-transplant to the last follow-up visit. Chronic kidney disease (CKD) stages were used as follows: stages $1-2$, GFR $>60 \mathrm{~mL} / \mathrm{min} / 1.73 \mathrm{~m}^{2}$; stage 3 , GFR 30 $59 \mathrm{~mL} / \mathrm{min} / 1.73 \mathrm{~m}^{2}$; stages $4-5$, GFR $<30 \mathrm{~mL} / \mathrm{min} / 1.73 \mathrm{~m}^{2}$ [23].

\section{Kidney graft biopsies}

Protocol biopsies taken at 3 months after renal transplantation were available from 31 patients with another control biopsy at the later time point (1.5 and 3 years post renal transplantation). Biopsies at 1.5 or 3 years after renal transplantation were available from $50 \mathrm{RTx}$ recipients. Renal histopathologic analysis was blindly performed (JL) according to the Banff ' 05 criteria [24]. The combination of interstitial fibrosis (IF) and tubular atrophy (TA) scores (IF + TA sum score of $\leq 1=\mathrm{IF} / \mathrm{TA}$ negative; IF+ TA sum score of $\geq 2=I F / T A$ positive) was used to describe chronic changes in allograft histology and related to anemia status. 


\section{Determination of EPO and hepcidin-25 levels}

The levels of EPO and hepcidin-25 were retrospectively analyzed from stored serum samples using enzyme-linked immunosorbent assay (ELISA) methods (EPO: Biovendor, Karasek, Czech Republic; hepcidin-25: DRG Instruments $\mathrm{GmbH}$, Marburg, Germany) according to the respective manufacturer's protocol. Samples for these analyses were collected as a part of the routine follow-up at various time points between 1.5 and 4 years after renal transplantation, and these variables were not followed longitudinally.

\section{Determination of hsCRP and IL-6 levels}

Levels of inflammatory markers hsCRP and IL-6 were determined in 747 and 764 serial serum samples, respectively. The samples were collected from stable patients without clinical signs of rejection or infection. HsCRP levels were measured using commercial ELISA kits (Circulex, Nagano, Japan), and IL-6 levels were assessed using the high-sensitivity ELISA kits of Diaclone (Besancon, France). Cut-off values for elevated hsCRP level were set to 1 and $3 \mathrm{mg} / \mathrm{L}$, as previously described [9].

\section{Statistical analysis}

Results are expressed as means and standard deviations for continuous variables with a normal distribution and as medians and interquartile ranges (25th to 75 th percentile, IQR) for parameters with a skewed distribution. The statistical significance of differences between the groups was tested using the $t$ test or Mann-Whitney $U$ test, Kruskall-Wallis and chisquare tests, as appropriate. The repeated measures analysis of variance was used for the longitudinal description of markers over time. Pearson's correlation coefficient and Spearman's rank test were used to assess the associations between variables. Abnormally distributed variables, namely, EPO, hepcidin-25, hsCRP and IL-6, were log-transformed before the linear regression analyses. Multivariable regression analyses were performed to identify independent predictors of continuous $\mathrm{Hb}$, hsCRP and ESR levels. All variables that correlated significantly in the univariable analysis were entered into the multivariable regression models. Two-sided $p$ values of $<0.05$ were considered to be statistically significant. All statistical analyses were performed using SPSS version 20.0 (IBM Corp., Armonk, NY).

\section{Results}

The 128 pediatric patients enrolled in this study underwent renal transplanation at the median age of 3.8 (IQR 1.7-9.3) years and were followed for a median of 10 (IQR 7-14) years
(Table 1). Nearly half (48\%) of the patients were transplanted due to congenital nephrotic syndrome of the Finnish type (CNF) and $22 \%$ due to congenital anomalies of the kidney and urinary tract (CAKUT). The mean GFR of the patients improved in the first 1.5 years after renal transplantation from 59 to $65 \mathrm{~mL} / \mathrm{min} / 1.73 \mathrm{~m}^{2}$ and decreased thereafter to $43 \mathrm{~mL} /$ $\min / 1.73 \mathrm{~m}^{2}$ at 10 years, with a mean annual GFR decline of $2.1 \pm 3.7 \mathrm{~mL} / \mathrm{min} 1.73 \mathrm{~m}^{2}$ per year. Nine patients required a retransplantation during the follow-up period.

\section{Anemia and blood count}

The mean blood $\mathrm{Hb}$ level increased clearly during the first year after transplantation and remained quite stable thereafter with a mean value of $115 \pm 15 \mathrm{~g} / \mathrm{L}$ in the 1580 samples taken at various time points between 1 and 10 years after transplantation. At 1 month after renal transplantation, $87 \%$ of the patients were anemic, but the prevalence decreased to $48 \%$ at 1.5 years and varied between 40 and $57 \%$ thereafter. CNF patients were more anemic at 3 months ( 70 vs. $42 \%$; $p=0.004)$ and 3 years (53 vs. $35 \% ; p=0.043$ ) following renal transplantation compared to patients with other

Table 1 Characteristics of the 128 pediatric renal transplant recipients enrolled in the study

\begin{tabular}{ll}
\hline Characteristics & Values \\
\hline Patients & 128 \\
$\quad$ Male/female & $84(66 \%) / 44(34 \%)$ \\
Disease leading to renal transplantation & \\
CNF & $61(48 \%)$ \\
CAKUT & $28(22 \%)$ \\
Other hereditary & $20(16 \%)$ \\
Inflammatory & $8(6 \%)$ \\
Other & $11(9 \%)$ \\
Age at transplantation, years & $3.8(1.7-9.3)$ \\
Deceased donor/living related donor & $94(73 \%) / 34(27 \%)$ \\
Cold ischemic time (h) & $18.4(4.2-22.3)$ \\
HLA mismatches & $2.27 \pm 1.14$ \\
AB mismatch & $1.55 \pm 0.85$ \\
DR mismatch & $0.72 \pm 0.55$ \\
CMV status & \\
Seropositive donor/seronegative recipient & $51(40 \%)$ \\
Duration of follow-up (years) & $10(7-14)$ \\
Graft loss & 11 \\
Deceased patients & 6 \\
\hline
\end{tabular}

Values in table are presented as the number of patients with/without the percentage in parenthesis, as the median with the interquartile range (IQR) in parenthesis or as the mean \pm standard deviation (SD), as appropriate

CNF, Congenital nephrotic syndrome of the Finnish type; CAKUT, congenital anomalies of the kidney and urinary tract; CMV, cytomegalovirus 
diagnoses. Anemia frequency during the maintenance phase did not increase in patients who had acute rejections during the first year. Also, donor age did not show any correlation with $\mathrm{Hb}$ levels during the follow-up (data not shown). Anemia was normocytic and normochromic in the great majority of patients (Table 2). Leucopenia and thrombocytopenia were more frequent in anemic patients than in non-anemic patients $[17$ vs. $8 \%(p<0.001)$ and 14 vs. $9 \%(p=0.004)$, respectively] (Table 2).

\section{Anemia and graft function}

Anemic patients had significantly lower simultaneous GFR values from 6 months to 8 years after renal transplantation than non-anemic recipients (Table 2 ; Fig. 1). The patients with CKD stage 1-2 had higher Hb levels (median $120 \mathrm{~g} / \mathrm{L}$ ) than those with CKD stage 3 and CKD stage 4-5 (median $113 \mathrm{~g} / \mathrm{L}$ and $110 \mathrm{~g} / \mathrm{L}$, respectively; $p<0.001$ for both).

Importantly, low $\mathrm{Hb}$ levels preceded decreased subsequent graft function. $\mathrm{Hb}$ levels at 1.5-2 years after renal transplantation, when the graft function was maximal, were significantly related to both concomitant $(r=0.328, p<0.001)$ and subsequent ( 6 years post renal transplantation) GFR levels $(r=0.516, p<0.001)$ (Figs. 2, 3). Patients with normal $\mathrm{Hb}$ showed a clear improvement in GFR after renal transplantation, reaching the mean peak level of $79 \mathrm{~mL} / \mathrm{min} / 1.73 \mathrm{~m}^{2}$ $(p<0.001)$ at 1.5 years, whereas patients with anemia at $>1$ year after renal transplantation only reached the peak level of $61 \mathrm{~mL} / \mathrm{min} / 1.73 \mathrm{~m}^{2}$. Thereafter, the slope of the annual decline in GFR was comparable ( 1.8 vs. $2.1 \mathrm{~mL} / \mathrm{min} /$ $\left.1.73 \mathrm{~m}^{2} ; p=0.664\right)$. The mean GFR values of children with anemia were $6-19 \mathrm{~mL} / \mathrm{min} / 1.73 \mathrm{~m}^{2}$ lower until the end of the 10 -year follow-up period. Interestingly, mean GFR decreased to $<60 \mathrm{~mL} / \mathrm{min} / 1.73 \mathrm{~m}^{2}$ at 2 years and 6 years in anemic patients and non-anemic patients, respectively.

The influence of anemia status $>1$ year on annual decline in GFR was shown by multivariable model $\left(R^{2}=0.421\right.$, $p=0.007)$, where the maximal GFR at $1.5-2$ years $(\beta=0.567, p<0.001)$ explained $27 \%$ of the variation and age-related anemia $(\beta=0.386, p=0.002)$ an additional $15 \%$.

\section{Anemia and biopsy findings}

Protocol biopsies at 1.5 and 3 years after renal transplantation showed IF/TA positive changes in 32 of the 50 patients $(64 \%)$. At the time of biopsy, anemia was evident in $50 \%$ (16/32) of the patients with fibrosis compared to $17 \%(3 / 18)$ in those with no fibrosis $(p=0.033)$. The mean $\mathrm{Hb}$ level was

Table 2 Characteristics and comparison of variables associated with anemia

\begin{tabular}{|c|c|c|c|c|c|c|c|c|c|}
\hline \multirow[t]{2}{*}{ Variables } & \multicolumn{2}{|l|}{ All patients } & \multicolumn{3}{|c|}{ Normal $\mathrm{Hb}$ patients } & \multicolumn{3}{|l|}{ Anemia patients } & \multirow[t]{2}{*}{$p$ value } \\
\hline & Value & $n$ & Value & Abnormal $(\%)^{\mathrm{a}}$ & $n$ & Value & Abnormal $(\%)^{\mathrm{a}}$ & $n$ & \\
\hline MCV (fL) & $85.9 \pm 5.2$ & 1604 & $85.8 \pm 5.0$ & 0.8 & 760 & $86.0 \pm 5.4$ & 1.3 & 843 & 0.330 \\
\hline MCH (pg/cell) & $29.0 \pm 2.6$ & 1604 & $29.3 \pm 2.9$ & 0.7 & 760 & $28.8 \pm 2.2$ & 3.0 & 843 & $<0.001$ \\
\hline $\mathrm{MCHC}(\mathrm{g} / \mathrm{L})$ & $337.1 \pm 11.9$ & 1601 & $339.9 \pm 10.6$ & 0.4 & 756 & $334.5 \pm 12.5$ & 1.5 & 844 & $<0.001$ \\
\hline Leucocytes $\left(10^{9} / \mathrm{L}\right)$ & $7.4 \pm 2.9$ & 1543 & $7.6 \pm 2.7$ & 8 & 717 & $7.2 \pm 3.0$ & 17 & 801 & 0.018 \\
\hline Neutrophils $\left(10^{9} / \mathrm{L}\right)$ & $3.8 \pm 2.1$ & 999 & $3.9 \pm 2.2$ & 0.8 & 509 & $3.6 \pm 2.0$ & 2 & 466 & 0.012 \\
\hline Thrombocytes $\left(10^{9} / \mathrm{L}\right)$ & $295.1 \pm 92.2$ & 1586 & $295.3 \pm 79.0$ & 9 & 742 & $295.5 \pm 102.9$ & 14 & 833 & 0.964 \\
\hline $\mathrm{EPO}(\mathrm{mIU} / \mathrm{mL})$ & $6.3(4.0-10.2)$ & 101 & $5.6(4.0-8.3)$ & 18 & 57 & $7.7(4.5-11.5)$ & 36 & 42 & 0.038 \\
\hline Hepcidin-25 (ng/mL) & $9.4(3.4-23.1)$ & 106 & $8.5(3.2-19.8)$ & 20 & 56 & $9.6(3.8-27.4)$ & 31 & 48 & 0.398 \\
\hline $\operatorname{HsCRP}(\mathrm{mg} / \mathrm{L})$ & $0.40(0.2-1.5)$ & 731 & $0.39(0.13-1.26)$ & 28 & 351 & $0.43(0.19-1.79)$ & 36 & 383 & 0.019 \\
\hline IL-6 (pg/mL) & $1.40(0.2-5.0)$ & 764 & $1.3(0.1-5.8)$ & 27 & 358 & $1.6(0.4-4.5)$ & 22 & 398 & 0.092 \\
\hline $\operatorname{ESR}(\mathrm{mm} / \mathrm{h})$ & $19(12-30)$ & 1512 & $16.0(10-25)$ & 23 & 715 & $22.5(15-35)$ & 42 & 783 & $<0.001$ \\
\hline \multicolumn{10}{|c|}{ GFR $\left(\mathrm{mL} / \mathrm{min} / 1.73 \mathrm{~m}^{2}\right)$ after renal transplantation } \\
\hline 0.5 years & $63.8 \pm 19.1$ & 115 & $69.6 \pm 19.2$ & 31 & 56 & $57.8 \pm 17.2$ & 79 & 58 & $<0.001$ \\
\hline 2 years & $60.9 \pm 18.7$ & 71 & $68.2 \pm 16.7$ & 32 & 38 & $52.5 \pm 17.5$ & 73 & 33 & $<0.001$ \\
\hline 6 years & $51.3 \pm 15.1$ & 105 & $58.1 \pm 14.7$ & 56 & 52 & $44.3 \pm 12.1$ & 89 & 53 & $<0.001$ \\
\hline 10 years & $44.8 \pm 14.1$ & 72 & $43.5 \pm 15.4$ & 89 & 36 & $42.3 \pm 12.9$ & 94 & 36 & 0.718 \\
\hline
\end{tabular}

Values in table are presented as the mean $\pm \mathrm{SD}$ or the median with the IQR in parenthesis, as appropriate

$\mathrm{Hb}$, Hemoglobin; MCV, mean cell volume; MCH, mean cell hemoglobin; MCHC, mean cell hemoglobin concentration; EPO, erythropoietin; HsCRP, high-sensitivity C-reactive protein; IL-6, interleukin-6; ESR, erythrocyte sedimentation rate; GFR, glomerular filtration rate

${ }^{\text {a }}$ Prevalence of abnormal/highest quartile and GFR of $<60 \mathrm{~mL} / \mathrm{min} / 1.73 \mathrm{~m}^{2}$ values

${ }^{\mathrm{b}} p$ values for the comparison between the normal $\mathrm{Hb}$ and anemia groups by the $t$ test or Mann-Whitney $U$ test 
Fig. 1 Box-plot of glomerular filtration rates $(G F R)$ at various time points $0.5-10$ years after renal transplantation in 128 pediatric patients, with the median value (thick horizontal line) and lowest and the highest quartiles (boxes) shown: a hemoglobin $(H b)$, b highsensitivity C-reactive protein (hsCRP), c interleukin-16 (IL-6), d erythrocyte sedimentation rate (ESR). Open circles Outliers, whiskers upper and lower extreme values, asterisk significance $(p<0.05)$

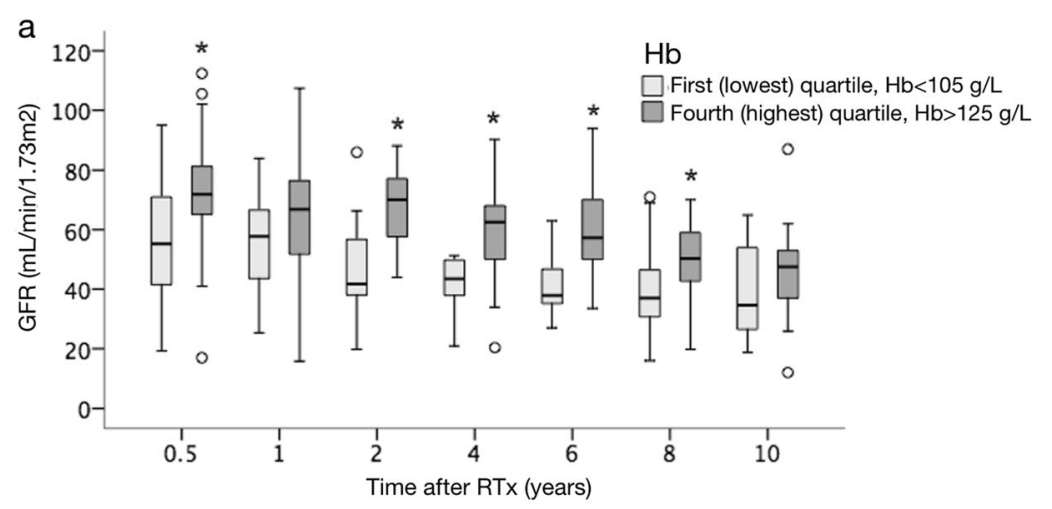

b

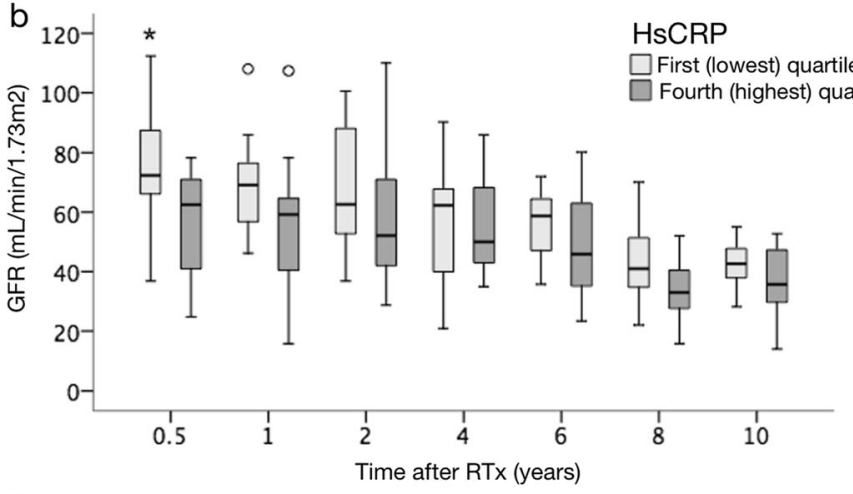

C
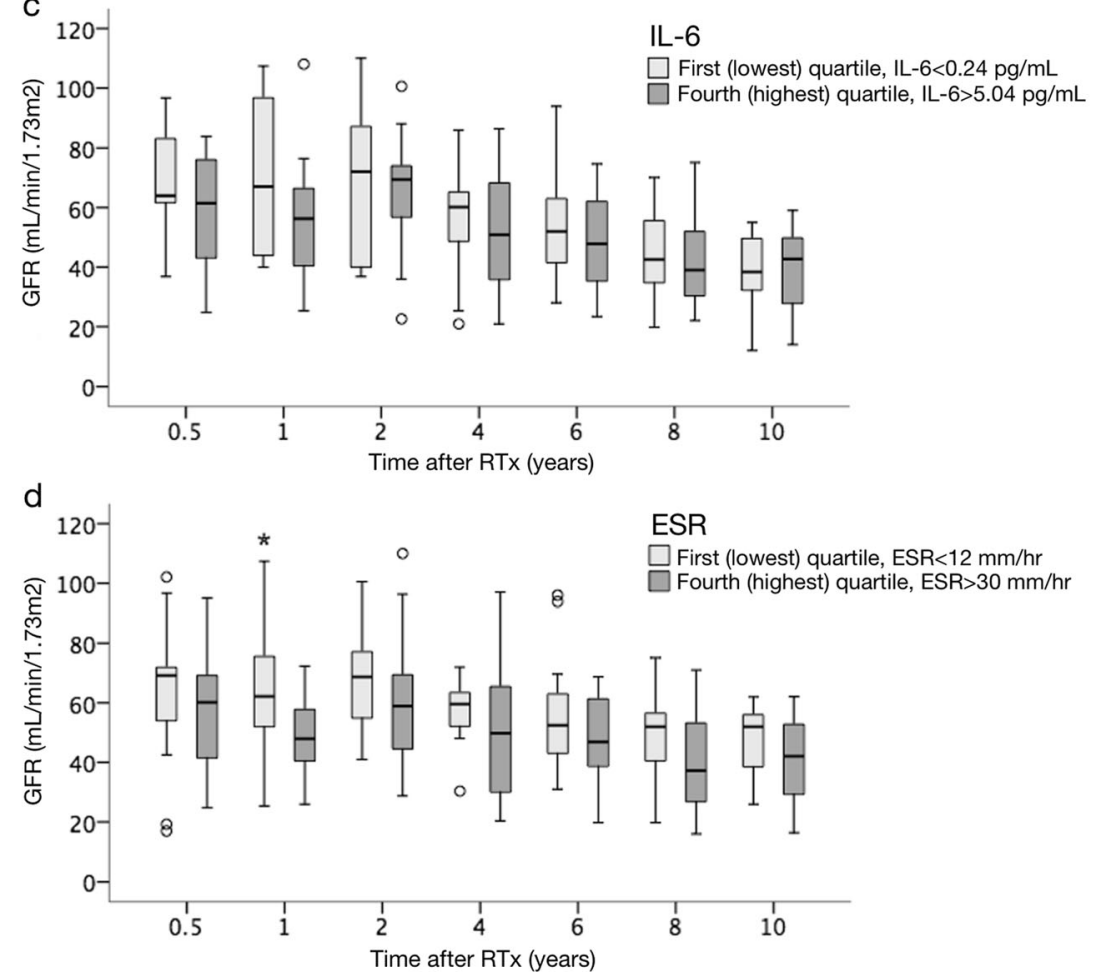

$115 \pm 12 \mathrm{~g} / \mathrm{L}$ in recipients with fibrosis compared to 121 $\pm 13 \mathrm{~g} / \mathrm{L}$ in those without $(p=0.034)$. In 145 blood samples drawn $0.5-2$ years before the biopsy (at least 1 year after renal transplantation), anemia was detected in 69 and $33 \%$ of the patients with and without fibrosis $(p=0.020)$, respectively, suggesting an association between low preceding $\mathrm{Hb}$ levels and increased graft fibrosis. This possible association was further studied in a subgroup of 31 patients for whom biopsy samples were also available at 3 months post renal transplantation. Based on analysis of these blood samples, 18 of these patients had no fibrosis at 3 months but developed it later, and more than half $(10 / 18)$ of these patients had anemia (mean $\mathrm{Hb}$ 
Fig. 2 Relationship between $\mathrm{Hb}$ and GFR (a), erythropoietin $(E P O ; \mathbf{b})$, hepcidin-25 (c), hsCRP (d), IL-6 (e) and ESR (f) at 1.52 years after renal transplantation ( $r$ Spearman's rank correlation). $H b$ hemoglobin; GFR glomerular filtration rate; $h s C R P$ high sensitivity C-reactive protein; ESR erythrocyte sedimentation rate a

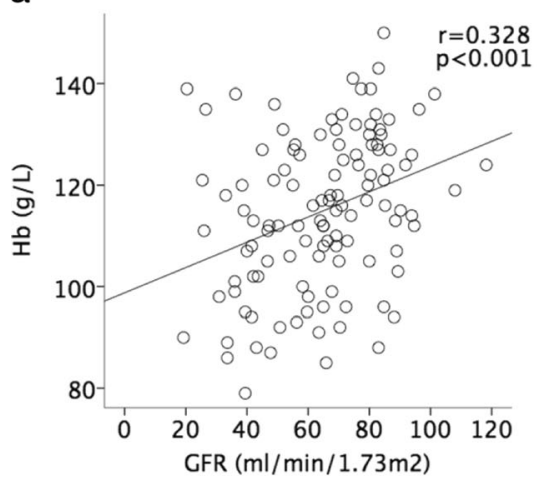

C

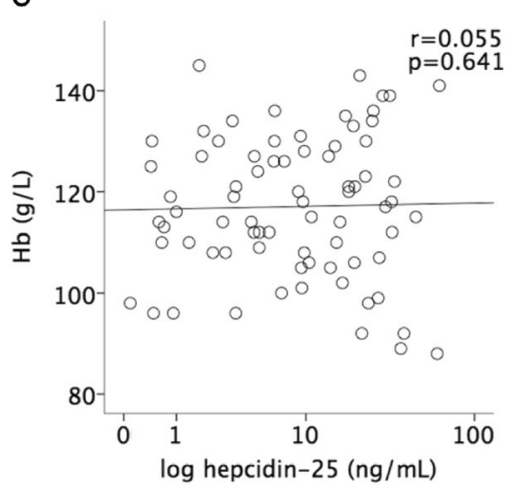

e

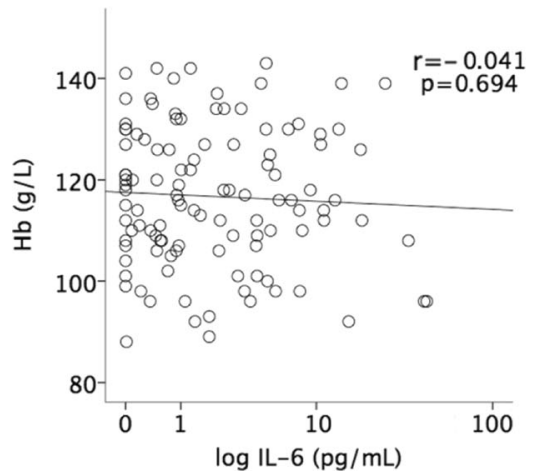

b

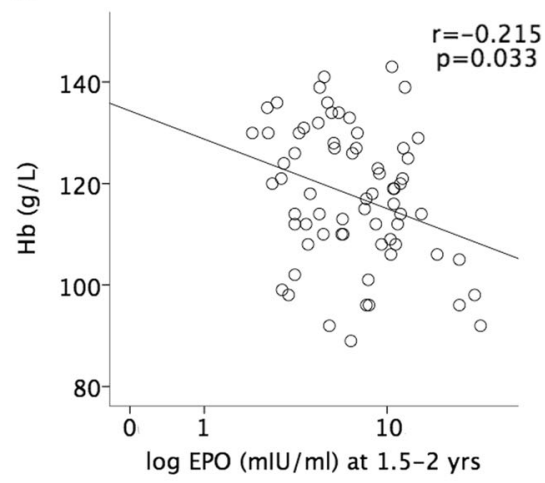

d

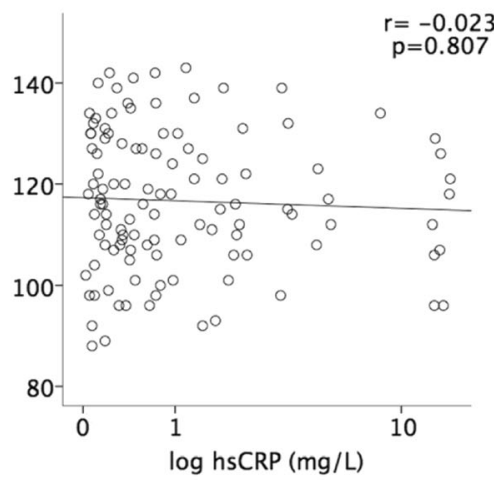

f

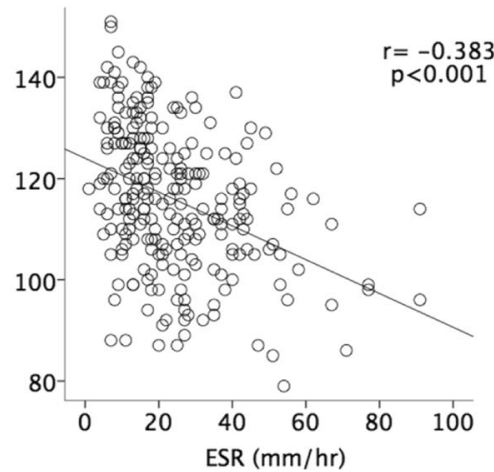

$114 \mathrm{~g} / \mathrm{L}$ ) at 1 year. The samples of nine patients showed no signs of fibrosis at 1 year post transplantation, and all had normal $\mathrm{Hb}$ levels (mean $133 \mathrm{~g} / \mathrm{L}$ ). Patients with fibrosis and anemia at the time of the 1.5- and 3-year biopsy showed a tendency for lower concomitant GFR $(55 \pm 16 \mathrm{~mL} / \mathrm{min} /$ $\left.1.73 \mathrm{~m}^{2}\right)$ than patients with fibrosis and normal $\mathrm{Hb}(65$ $\pm 20 \mathrm{~mL} / \mathrm{min} / 1.73 \mathrm{~m}^{2} ; p=0.132$ ).

\section{Erythropoietin}

Serum EPO levels were somewhat higher in anemic patients than in those with normal Hb levels (median 7.7 vs. $5.6 \mathrm{mIU} /$ $\mathrm{mL} ; p=0.038$ ) based on analysis of 101 samples collected at
1.5-4 years after renal transplantation (Table 2). The EPO level showed an inverse correlation with $\mathrm{Hb}$ concentration ( $r=-0.215, p=0.033$ ) (Table 3; Fig. 2). Measured EPO levels in CNF patients at 1.5-4 years after renal transplantation were significantly lower than those in other patients (5.1 vs. 7.6; $p=0.003$ ) and additional EPO use was more common (48 vs. $19 \%$, respectively; $p=0.001$ ). Univariable analysis showed a positive correlation between EPO and hsCRP levels $(r=0.248, p=0.014)$, but this association did not retain significance $(\beta=0.159, p=0.146)$ in the multivariable model (Table 3). EPO levels were unrelated to concurrent $(r=0.029, p=0.786)$ and subsequent $(r=0.076, p=0.462)$ GFR levels (Fig. 3). 
Fig. 3 Relationship between GFR at 6 years after renal transplantation and $\mathrm{Hb}(\mathbf{a}), \mathrm{EPO}$ (b), hepcidin-25 (c), hsCRP (d), IL-6 (e) and ESR (f) at 1.5-

2 years after renal transplantation ( $r$ Spearman's rank correlation).

$\mathrm{Hb}$ hemoglobin; $E P O$

erythropoietin; ESR erythrocyte

sedimentation rate; $G F R$

glomerular filtration rate a

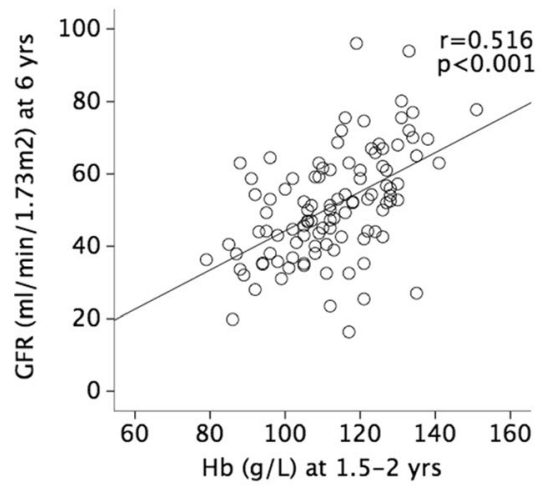

C

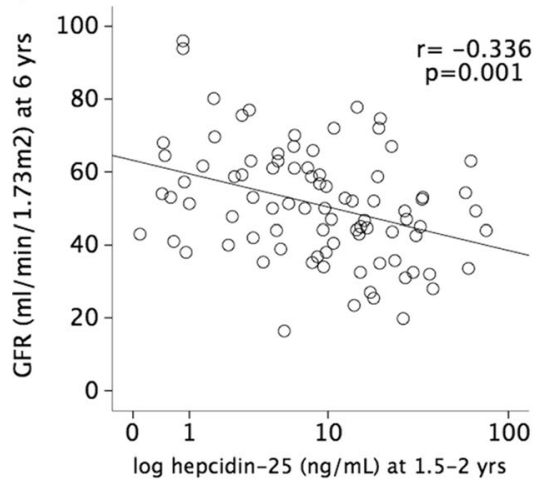

e

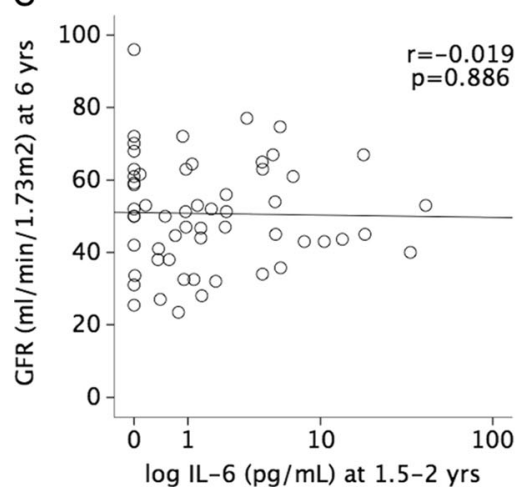

b

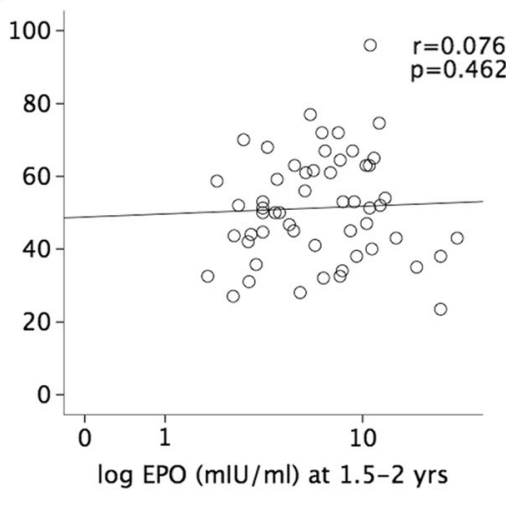

d

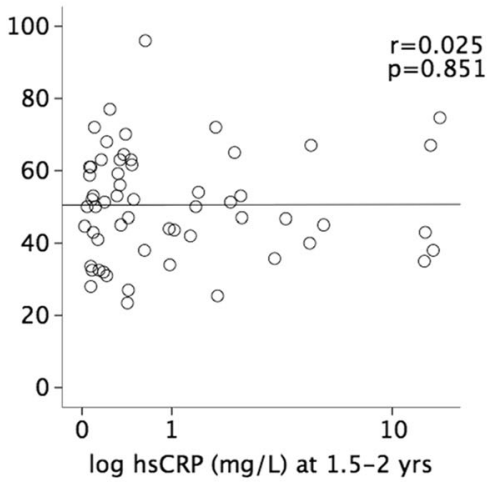

f

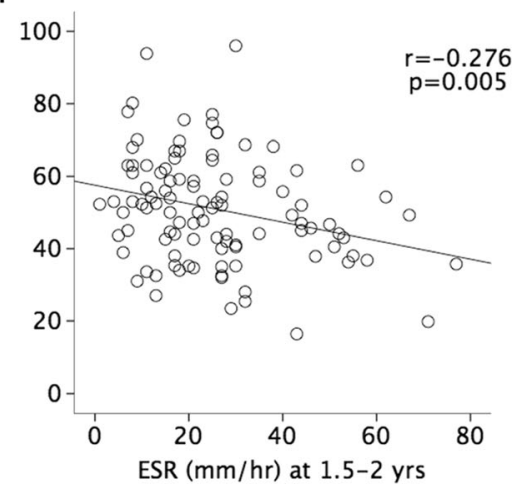

\section{Hepcidin-25}

Serum hepcidin-25 level was measured in 106 serum samples drawn at 1.5-4 years after renal transplantation, with a median value of 9.4 (IQR 3.4-23.1) ng/mL. Hepcidin-25 level was unrelated to $\mathrm{Hb}$ concentration $(r=-0.052, p=0.603)$ (Table 3; Fig. 2). Surprisingly, hepcidin-25 levels were inversely correlated with the concomitant GFR $(r=-0.305, p=0.006)$ and the values at $1.5-2$ years after renal transplantation predicted GFR at 6 years $(r=-0.336, p=0.001)$ (Fig. 3$)$. In the multivariable model $\left(R^{2}=0.338, p=0.005\right) \mathrm{Hb}$ level at $1.5-2$ years post renal transplantation $(\beta=0.424, p<0.001)$ explained $25 \%$ of the variation in GFR level at 6 years and hepcidin-
25 level $(\beta=-0.261, p=0.005)$ explained an additional $9 \%$ (Fig. 3).

\section{High-sensitivity CRP}

High-sensitivity CRP levels were measured in 731 blood samples drawn at various time points between 1 month and 10 years after renal transplantation. The median hsCRP value was 0.40 (IQR $0.16-1.48) \mathrm{mg} / \mathrm{L}$, with no significant association with time since renal transplantation. In total, 31 and $13 \%$ of the hsCRP values were $>1$ and $>3 \mathrm{mg} / \mathrm{L}$, respectively, indicating low-grade inflammation. 


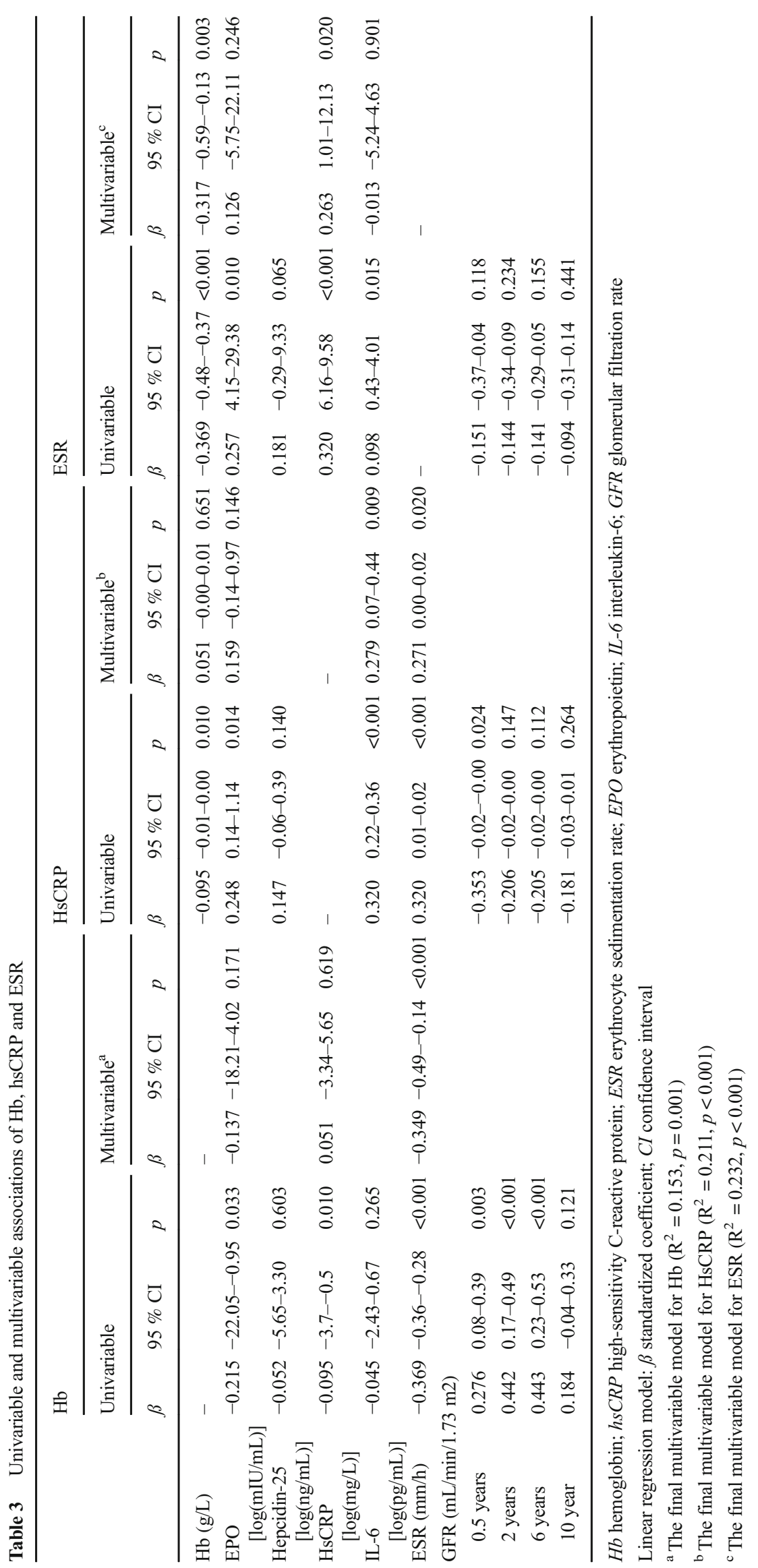


Elevated hsCRP levels were seen in $36 \%$ of anemic versus $28 \%$ of non-anemic patients ( $p=0.038$; Table 2$)$. A weak negative correlation between hsCRP and Hb levels was evident only in the univariable $(r=-0.095, p=0.010)$ analysis of all 731 samples (Table 3), but not in samples obtained at 1.5-2 years post-RTx when the graft function was maximal ( $r=-0.023, p=0.807$ ) (Fig. 2). HsCRP levels were comparable (2.3 vs. $1.6 \mathrm{mg} / \mathrm{L}, p=0.397)$ between patients with and without acute rejection during the first year after renal transplantation. Similarly, donor age $(r=0.102, p=0.406)$ showed no correlation with hsCRP levels. These findings were also observed with other inflammatory markers.

HsCRP values showed only a weak correlation with kidney graft function (Table 3). In samples taken at various time points between 0.5 and 10 years after renal transplantation, low hsCRP values tended to associate with higher GFR, as shown in Fig. 1. However, after the first 0.5 years hsCRP values were unrelated to GFR levels (Table 3). Also, the hsCRP levels at 1.5-2 years post-RTx had no predictive value for subsequent GFR (Fig. 3).

\section{Interleukin-6}

Serum IL-6 concentration was assessed in 764 samples, with a median level of 1.4 (IQR 0.24-5.04) pg/mL. The levels were significantly elevated at 1 month after renal transplantation compared to the later period (median 3.3 vs. $1.29 \mathrm{pg} / \mathrm{mL}$; $p=0.004)$. IL-6 level showed a positive correlation with hsCRP $(r=0.320, p<0.001)$ but not with hepcidin-25 $(r=0.091, p=0.421)$.

IL-6 levels were similar in the anemic and non-anemic patients (median 1.6 vs. $1.3 \mathrm{pg} / \mathrm{mL} ; p=0.092$ ) (Table 2 ), and the values showed no association with the $\mathrm{Hb}$ levels in the univariable analyses (Table 3; Fig. 2). Also, we found no correlation between the IL-6 levels with the concomitant or subsequent GFR values at any time point (Figs. 1, 3).

\section{Erythrocyte sedimentation rate}

The ESR was recorded in 1512 blood samples, with a median level of 19.0 (IQR 12-30) mm/h. Elevated ESR (>25 mm/h) was seen in $33 \%$ of the samples throughout the follow-up, and ERS levels showed a positive correlation with hsCRP values $(r=0.320, p<0.001)$ (Table 3$)$. The median ESR value was $22.5 \mathrm{~mm} / \mathrm{h}$ in the anemic and $16.0 \mathrm{~mm} / \mathrm{h}$ in the nonanemic patients $(p<0.001$, Table 2$)$. ESR values also showed a strong negative correlation with $\mathrm{Hb}$ levels at $1.5-2$ years after renal transplantation $(r=-0.383, p<0.001)$ and in univariable and multivariable analyses of samples from different time points $(\beta=-0.369, p<0.001)$ (Table 3$)$.

As shown in Fig. 1, patients with high ESR showed a lower GFR during the follow-up, but this was statistically significant $(p<0.05)$ only at 1 year after renal transplantation. ESR levels at 1.5-2 years after renal transplantation showed a negative correlation $(r=-0.276, p=0.005)$ with the GFR levels at 6 years in the univariable analysis (Fig. 3), but the predictive value of ESR on GFR level was no longer significant in the multivariable analysis. The ESR levels increased along the CKD stages, from $21 \mathrm{~mm} / \mathrm{h}$ in the patients with CKD stage 1-2 to $23 \mathrm{~mm} / \mathrm{h}$ and $27 \mathrm{~mm} / \mathrm{h}$ in those with CKD stage 3 and CKD stage $4-5$, respectively ( $p=0.003)$.

\section{Combining markers of anemia and inflammation}

Patients with simultaneously elevated ESR of $>25 \mathrm{~mm} / \mathrm{h}$ and hsCRP of $>1 \mathrm{mg} / \mathrm{L}$ showed decreased concurrent GFR at 0.5 years after renal transplantation when compared to those who did not (50.4 vs. $69.4 \mathrm{~mL} / \mathrm{min} / 1.73 \mathrm{~m}^{2} ; p=0.001$ ). This was not seen at other time points. Moreover, GFR levels in patients with simultaneously elevated hsCRP and IL-6 levels did not differ from those in other patients.

Combined anemia and high ESR level at 1.5-2 years after renal transplantation was associated with decreased concomitant and subsequent GFR up to 8 years after renal transplantation ( $p<0.05$ for all). However, anemia status $(\beta=-0.401$, $p<0.001)$ explained $19 \%$ of the variation in GFR at 6 years and elevated ESR level $(\beta=-0.147, p=0.107)$ explained only an additional $2 \%\left(R^{2}=0.211, p=0.107\right)$. A similar analysis of combined anemia and elevated hsCRP or IL-6 level showed an insignificant effect of elevated inflammatory indices on GFR.

\section{Discussion}

We found low $\mathrm{Hb}$ and elevated inflammatory marker levels in a substantial proportion of pediatric Rtx patients throughout the 10-year post-operative follow-up. Hb levels showed an inverse correlation with EPO and ESR values but not with hepcidin-25, IL-6 or hsCRP levels. Hb levels also showed a strong inverse correlation with the measured GFR values, and anemia predicted reduced long-term graft function in these patients. In contrast, the inflammatory markers correlated poorly with the concurrent and future GFR values and did not bring additional diagnostic value to the $\mathrm{Hb}$ measurements. These results suggest that anemia, but not low-grade inflammation, is associated with impaired graft function in pediatric RTx patients.

We found an anemia frequency of $87 \%$ during the early months after renal transplantation, decreasing to 40-56\% during the subsequent $1-10$ years. This result is in line with previous reports both in adult and pediatric RTx patients, especially during the first months after the operation $[1,25,26]$. In the study of Yorgin et al. [27] on 162 pediatric RTx patients, the peak anemia (hematocrit) prevalence (84\%) was observed 1 month after RTx, with the percentage remaining high 
(64-82 \%) during the 5-year follow-up. In that study, early anemia was less frequent in patients younger than 2 years at renal transplantation in comparison with older children. In our cohort, the youngest children were more anemic, which may be due to the high prevalence ( $76 \%$ ) of young CNF patients who were more anemic at the early phase and also later on. Also, the measured EPO levels at 1.5-4 years after renal transplantation were significantly lower among CNF patients and additional EPO use was more common, possibly reflecting the effect of bilateral nephrectomy prior to renal transplantation. The differences between CNF and other patients is, however, difficult to explain over the long term because long-term graft function is comparable in CNF and other patients [20]. Also, the basic defect in CNF, namely, lack of the podocyte protein nephrin, should not predispose these children to anemia.

An important but yet unresolved question is what causes anemia in RTx patients [28, 29]. We found leucopenia and thrombocytopenia in only a small proportion of the anemic patients (17 and $14 \%$, respectively), suggesting that generalized bone marrow suppression may be the cause in some, but not in the majority, of the patients. Iron deficiency may lead to anemia and has been reported in over $30 \%$ of pediatric RTx patients $[27,30]$. In our cohort, only $1-3 \%$ of the anemic patients had microcytosis or hypochromia. In a subgroup analysis of 39 patients, only two patients had simultaneous anemia, microcytosis and low transferrin saturation (data not shown). Also, hepcidin-25 levels were not decreased in our anemic patients, suggesting that iron deficiency is the cause of anemia in only a minority of patients. This fits to our clinical experience that iron therapy is quite rarely helpful in anemic RTx patients.

Low-grade inflammation is a clinical challenge during the post-transplant period and may induce anemia $[17,31]$. We analyzed the association of the inflammatory markers IL-6, hsCRP and ESR with the $\mathrm{Hb}$ levels during the 10-year follow-up and especially at the early maintenance phase when graft function was still good in most patients. The results show that IL-6 and hsCRP values did not correlate with $\mathrm{Hb}$ levels and that the values were similar in anemic and non-anemic patients, speaking against a strong association between inflammatory processes and anemia. On the other hand, ESR values correlated negatively with the $\mathrm{Hb}$ levels, and anemic patients had higher ESR values. Little is known about the behavior of ESR after transplantation, but the data on CKD and dialysis patients suggest that the ESR values are affected by several factors, such as plasma fibrinogen, ferritin, platelet and white cell counts as well as hematocrit [32].

The interesting question which remains to be answered is: Which comes first - anemia or kidney graft injury? Fibrosis may impair the production of EPO by the peritubular cells, leading to anemia [33], which fits with our finding of an association between $\mathrm{Hb}$ levels and IF/TA findings in the protocol biopsy samples. On the other hand, it is known that low $\mathrm{Hb}$ levels may associate with tissue hypoxia, possibly accelerating the development of chronic allograft injury [34-37]. The importance of graft function was shown in a multicenter study by Choukroun et al. who demonstrated that normalization of $\mathrm{Hb}$ levels by exogenous EPO slowed down the decrease of GFR levels and reduced the incidence of end-stage renal disease in adult RTx patients [38]. In our study, anemia seemed to appear before renal fibrosis (1.5- and 3-year protocol biopsies), as $56 \%$ of the RTx patients who developed fibrosis after the 3-month biopsy were anemic at 1 year post surgery compared to none among those patients with no fibrosis at any biopsy $(p=0.009)$.

Our anemic patients showed up to a $23 \%$ decrease in the measured GFR at each time point during the 10-year followup, thereby verifying the previous cross-sectional observations on the association between the poor graft function and low $\mathrm{Hb}$ levels [1, 5, 27, 39, 40]. EPO is the main regulator of erythropoiesis, and anemia may be attributed to insufficient EPO production by the failing graft. However, the frequency of anemia did not increase with time and, at the early maintenance phase, EPO levels were higher, not lower, in anemic patients. Consistent with our results, serum EPO levels were inversely associated with $\mathrm{Hb}$ levels, but unrelated to GFR levels in a study conducted by Sinnamon and co-workers [41]. Adult RTx patients with anemia have been shown to present an additional $25 \%$ risk for renal graft loss [42], and increased risk for mortality $[6,26,43]$. The small number of graft losses among the patients in our study did not allow us to analyze the impact of low $\mathrm{Hb}$ levels on terminal graft failure.

Low $\mathrm{Hb}$ levels predicted reduced graft function by several years in our patients. Somewhat surprisingly, the inflammatory markers IL-6, hsCRP and ESR did not correlate with concurrent or future graft function. Also, no benefit was acquired by combining the marker findings. A marginal association was, however, found between the hepcidin- 25 and subsequent GFR levels $(p=0.006)$. In adult RTx patients, low-grade inflammation has been associated with increased mortality, caused by increased occurrence of cardiovascular complications [7]. In pediatric patients these events are extremely rare and were not observed in our cohort.

The strengths of our study were its longitudinal study design, extensive follow-up of $\mathrm{Hb}$ and inflammatory marker concentrations as well as annual GFR assessment by ${ }^{51} \mathrm{Cr}$ EDTA clearance for up to 10 years after renal transplantation. Our study also has a number of limitations, including the retrospective data collection and the single measurement of EPO and hepcidin-25 levels, which limit the conclusions on causality. Also, it was not possible to study the impact of different immunosuppressive drugs as the immunosuppressive protocol, including low-dose methylprednisolone, calcineurin inhibitors (cyclosporine A or tacrolimus) and antimetabolite (azathioprine or mycophenolate), was individualized and changed over time, excluding a meaningful analysis. 
However, the increase in the use of tacrolimus + mycophenolate combination therapy in recent years, compared to the 1990s when azathioprine + cyclosporine A was the major combination therapy, has not resulted in any change in the frequency of anemia or elevated inflammatory markers (data not shown).

In conclusion, our study confirms previous cross-sectional findings that anemia is common among pediatric RTx patients years after the operation. The $\mathrm{Hb}$ levels correlated negatively with the concomitant and future graft function. In contrast, inflammatory markers hsCRP and IL-6 did not associate with $\mathrm{Hb}$ levels or GFR. A better understanding of the pathophysiology of anemia-associated deterioration of the graft function appears to be important, and it is possible that early correction of low $\mathrm{Hb}$ levels might slow down this process.

Acknowledgments We thank Tuike Helmiö for her excellent technical assistance. This study was supported by the grants from the Sigrid Juselius Foundation, the Päivikki and Sakari Sohlberg Foundation, the Orion Research Foundation, the Finnish Kidney Foundation, the Foundation for Pediatric Research, and the Helsinki University Hospital Fund.

Compliance with ethical standards The Ethics Committee of the Children's Hospital, University of Helsinki and Helsinki University Hospital, approved this study.

Conflicts of interest J.L has received a lecture fee from Roche and is currently working at Finnish Red Cross Blood Service, which sells blood products to hospitals. The other authors declare that they have no conflicts of interest.

\section{References}

1. Krischock LA, van Stralen KJ, Verrina E, Tizard EJ, Bonthuis M, Reusz G, Hussain FK, Jankauskiene A, Novljan G, SpasojevicDimitrijeva B, Podracka L, Zaller V, Jager KJ, Schaefer F, ESPN/ ERA-EDTA Registry (2016) Anemia in children following renal transplantation-results from the ESPN/ERA-EDTA registry. Pediatr Nephrol 31:325-333

2. Molnar MZ, Mucsi I, Macdougall IC, Marsh JE, Yaqoob M, Main J, Courtney AE, Fogarty D, Mikhail A, Choukroun G, Short CD, Covic A, Goldsmith DJ (2011) Prevalence and management of anaemia in renal transplant recipients: data from ten European centres. Nephron Clin Pract 117:c127-c134

3. Shah N, Al-Khoury S, Afzali B, Covic A, Roche A, Marsh J, Macdougall IC, Goldsmith DJ (2006) Posttransplantation anemia in adult renal allograft recipients: prevalence and predictors. Transplantation 81:1112-1118

4. Vanrenterghem Y, Ponticelli C, Morales JM, Abramowicz D, Baboolal K, Eklund B, Kliem V, Legendre C, Morais Sarmento AL, Vincenti F (2003) Prevalence and management of anemia in renal transplant recipients: a European survey. Am J Transplant 3:835-845

5. Al-Khoury S, Shah N, Afzali B, Covic A, Taylor J, Goldsmith D (2006) Post-transplantation anaemia in adult and paediatric renal allograft recipients-guy's hospital experience. Nephrol Dial Transplant 21:1974-1980
6. Molnar MZ, Czira M, Ambrus C, Szeifert L, Szentkiralyi A, Beko G, Rosivall L, Remport A, Novak M, Mucsi I (2007) Anemia is associated with mortality in kidney-transplanted patients - a prospective cohort study. Am J Transplant 7:818-824

7. Abedini S, Holme I, Marz W, Weihrauch G, Fellstrom B, Jardine A, Cole E, Maes B, Neumayer HH, Gronhagen-Riska C, Ambuhl P, Holdaas H, ALERT study group (2009) Inflammation in renal transplantation. Clin J Am Soc Nephrol 4:1246-1254

8. Dahle DO, Mjoen G, Oqvist B, Scharnagl H, Weihrauch G, Grammer T, Marz W, Abedini S, Norby GE, Holme I, Fellstrom B, Jardine A, Holdaas H (2011) Inflammation-associated graft loss in renal transplant recipients. Nephrol Dial Transplant 26:3756-3761

9. van Ree RM, Oterdoom LH, de Vries AP, Gansevoort RT, van der Heide JJ, van Son WJ, Ploeg RJ, de Jong PE, Gans RO, Bakker SJ (2007) Elevated levels of C-reactive protein independently predict accelerated deterioration of graft function in renal transplant recipients. Nephrol Dial Transplant 22:246-253

10. Sun CH, Ward HJ, Paul WL, Koyle MA, Yanagawa N, Lee DB (1989) Serum erythropoietin levels after renal transplantation. N Engl J Med 321:151-157

11. Beshara S, Birgegard G, Goch J, Wahlberg J, Wikstrom B, Danielson BG (1997) Assessment of erythropoiesis following renal transplantation. Eur J Haematol 58:167-173

12. Nampoory MR, Johny KV, al-Hilali N, Seshadri MS, Kanagasabhapathy AS (1996) Erythropoietin deficiency and relative resistance cause anaemia in post-renal transplant recipients with normal renal function. Nephrol Dial Transplant 11:177-181

13. Wagner M, Alam A, Zimmermann J, Rauh K, Koljaja-Batzner A, Raff U, Wanner C, Schramm L (2011) Endogenous erythropoietin and the association with inflammation and mortality in diabetic chronic kidney disease. Clin J Am Soc Nephrol 6: 1573-1579

14. Mercadal L, Metzger M, Casadevall N, Haymann JP, Karras A, Boffa JJ, Flamant M, Vrtovsnik F, Stengel B, Froissart M, NephroTest Study Group (2012) Timing and determinants of erythropoietin deficiency in chronic kidney disease. Clin J Am Soc Nephrol 7:35-42

15. Van Loo A, Vanholder R, Bernaert P, De Roose J, Lameire N (1996) Recombinant human erythropoietin corrects anaemia during the first weeks after renal transplantation: a randomized prospective study. Nephrol Dial Transplant 11:1815-1821

16. Gabay C (2006) Interleukin-6 and chronic inflammation. Arthritis Res Ther 8(Suppl 2):S3

17. Roy CN (2010) Anemia of inflammation. Hematol Am Soc Hematol Educ Program 2010:276-280

18. Raj DS (2009) Role of interleukin-6 in the anemia of chronic disease. Semin Arthritis Rheum 38:382-388

19. Chan W, G Ward D, McClean A, A Bosch J, Jones D, Kaur O, Drayson M, Whitelegg A, Iqbal T, McTernan PG, Tselepis C, Borrows R (2013) The role of hepcidin-25 in kidney transplantation. Transplantation 95:1390-1395

20. Tainio J, Qvist E, Holtta T, Pakarinen M, Jahnukainen T, Jalanko H (2014) Metabolic risk factors and long-term graft function after paediatric renal transplantation. Transpl Int 27:583-592

21. Fleming JS, Zivanovic MA, Blake GM, Burniston M, Cosgriff PS, British Nuclear Medicine Society (2004) Guidelines for the measurement of glomerular filtration rate using plasma sampling. Nucl Med Commun 25:759-769

22. Jodal L, Brochner-Mortensen J (2009) Reassessment of a classical single injection 51Cr-EDTA clearance method for determination of renal function in children and adults. part I: analytically correct relationship between total and one-pool clearance. Scand J Clin Lab Invest 69:305-313

23. Karthikeyan V, Karpinski J, Nair RC, Knoll G (2004) The burden of chronic kidney disease in renal transplant recipients. Am J Transplant 4:262-269 
24. Solez K, Colvin RB, Racusen LC, Sis B, Halloran PF, Birk PE, Campbell PM, Cascalho M, Collins AB, Demetris AJ, Drachenberg CB, Gibson IW, Grimm PC, Haas M, Lerut E, Liapis H, Mannon RB, Marcus PB, Mengel M, Mihatsch MJ, Nankivell BJ, Nickeleit V, Papadimitriou JC, Platt JL, Randhawa P, Roberts I, SalinasMadriga L, Salomon DR, Seron D, Sheaff M, Weening JJ (2007) Banff ' 05 meeting report: differential diagnosis of chronic allograft injury and elimination of chronic allograft nephropathy ('CAN'). Am J Transplant 7:518-526

25. Poesen R, Bammens B, Claes K, Kuypers D, Vanrenterghem Y, Monbaliu D, Evenepoel P (2011) Prevalence and determinants of anemia in the immediate postkidney transplant period. Transpl Int 24:1208-1215

26. Jones H, Talwar M, Nogueira JM, Ugarte R, Cangro C, Rasheed H, Klassen DK, Weir MR, Haririan A (2012) Anemia after kidney transplantation; its prevalence, risk factors, and independent association with graft and patient survival: a time-varying analysis. Transplantation 93:923-928

27. Yorgin PD, Belson A, Sanchez J, Al Uzri AY, Sarwal M, Bloch DA, Oehlert J, Salvatierra O, Alexander SR (2002) Unexpectedly high prevalence of posttransplant anemia in pediatric and young adult renal transplant recipients. Am J Kidney Dis 40:1306-1318

28. Galutira PJ, Del Rio M (2012) Understanding renal posttransplantation anemia in the pediatric population. Pediatr Nephrol 27:1079-1085

29. Reindl-Schwaighofer R, Oberbauer R (2014) Blood disorders after kidney transplantation. Transplant Rev 28:63-75

30. Kausman JY, Powell HR, Jones CL (2004) Anemia in pediatric renal transplant recipients. Pediatr Nephrol 19:526-530

31. Cueto-Manzano AM, Morales-Buenrostro LE, Gonzalez-Espinoza L, Gonzalez-Tableros N, Martin-del-Campo F, Correa-Rotter R, Valera I, Alberu J (2005) Markers of inflammation before and after renal transplantation. Transplantation 80:47-51

32. Brouillard M, Reade R, Boulanger E, Cardon G, Dracon M, Dequiedt P, Pagniez D (1996) Erythrocyte sedimentation rate, an underestimated tool in chronic renal failure. Nephrol Dial Transplant 11:2244-2247

33. Jelkmann W (2011) Regulation of erythropoietin production. J Physiol 589:1251-1258
34. Fine LG, Norman JT (2008) Chronic hypoxia as a mechanism of progression of chronic kidney diseases: from hypothesis to novel therapeutics. Kidney Int 74:867-872

35. Gurlek Demirci B, Sezer S, Sayin CB, Tutal E, Uyar ME, Ozdemir Acar FN, Haberal M (2015) Post-transplantation anemia predicts cardiovascular morbidity and poor graft function in kidney transplant recipients. Transplant Proc 47:1178-1181

36. Huang E, Bunnapradist S (2012) Transplantation: does anemia correction delay kidney allograft dysfunction? Nat Rev Nephrol 8:196-198

37. Kamar N, Rostaing L (2008) Negative impact of one-year anemia on long-term patient and graft survival in kidney transplant patients receiving calcineurin inhibitors and mycophenolate mofetil. Transplantation 85:1120-1124

38. Choukroun G, Kamar N, Dussol B, Etienne I, Cassuto-Viguier E, Toupance O, Glowacki F, Moulin B, Lebranchu Y, Touchard G, Jaureguy M, Pallet N, Le Meur Y, Rostaing L, Martinez F, CAPRIT study Investigators (2012) Correction of postkidney transplant anemia reduces progression of allograft nephropathy. J Am Soc Nephrol 23:360-368

39. Pascual J, Jimenez C, Franco A, Gil M, Obrador-Mulet AR, Gentil MA, Romero R, Grinyo JM, Hernandez D, Morales JM, Pallardo LM, Seron D, Arias M, Campistol J, ANEMIART Study Group (2013) Early-onset anemia after kidney transplantation is an independent factor for graft loss: A multicenter, observational cohort study. Transplantation 96:717-725

40. Mitsnefes MM, Subat-Dezulovic M, Khoury PR, Goebel J, Strife CF (2005) Increasing incidence of post-kidney transplant anemia in children. Am J Transplant 5:1713-1718

41. Sinnamon KT, Courtney AE, Maxwell AP, McNamee PT, Savage G, Fogarty DG (2007) Level of renal function and serum erythropoietin levels independently predict anaemia post-renal transplantation. Nephrol Dial Transplant 22:1969-1973

42. Winkelmayer WC, Chandraker A, Alan Brookhart M, Kramar R, Sunder-Plassmann G (2006) A prospective study of anaemia and long-term outcomes in kidney transplant recipients. Nephrol Dial Transplant 21:3559-3566

43. Chhabra D, Grafals M, Skaro AI, Parker M, Gallon L (2008) Impact of anemia after renal transplantation on patient and graft survival and on rate of acute rejection. Clin J Am Soc Nephrol 3:1168-1174 